\title{
Cyborgs and entanglements of technology, masculinity, and (automated) vehicles
}

\section{Introduction}

In this article, we draw on our previous research experiences (cf. Balkmar 2012, 2014; Balkmar \& Joelsson 2009, 2010, 2012, 2014; Mellström 1999, 2002, 2003a, 2003b, 2004, 2012) to discuss a number of key points on the cyborgic entanglements of technology, masculinity, and (automated) vehicles. In our previous work, different forms of relations between gender, bodies, and technologies of movement (such as cars, trucks, mopeds, bicycles, and computers) have formed a reoccurring theme - including emotionality and embodiment. Donna Haraway's visionary feminist cyborg figuration has been particularly important for opening up creative spaces to co-think (hu)man-machine, animal-human, nature-culture relations. Consequently, machines, cars, and other vehicles can be thought of as part of our embodiment, even as part of "us", as opposed to being ontologically or epistemologically separated (Balkmar \& Joelsson 2009, 121; Urry 2007, 127). In this article, it is our aim to use the potentials of the cyborg figuration as a double-edged figure. In line with Balkmar \& Joelsson (2009), we believe that the cyborg figuration is apt "both for feminist opposition and for teaming up with and sustaining the power of traditional notions of masculinity" (Balkmar \& Joelsson 2009, 121). Even though we will highlight emancipatory potentials of cyborgs, we will also »emphasise the politics of cyborg ontology mostly in terms of how it sustains the power of traditional notions of masculinity constructed through cultural discourse of masculinity, erotic and pleasurable relations between human and nonhuman actors" (Balkmar \& Joelsson 2009, 121).

To illustrate how cyborgs are political, we argue that a history of masculinity as well as the future of masculinity, in a Western context and beyond, can be understood in relation to cyborgisation and intimacy with technological artefacts. With a point of departure in a posthuman understanding and cyborg-epistemology formulated as "thesis, anti-thesis, synthesis, prosthesis" (Gray 2001, 189), we will, in this article, entangle and disentangle different discourses and practices by asking how masculinity 
has been constructed around intimacy, technology, and cyborgisation. Historically, such relations point in two different directions: On the one hand destructiveness, on the other emancipatory hopes of transcendence through cyborgisation. As illustrations of these two different directions, we will first revisit the historical foundation of the cyborgic entanglement of technology and masculinity, then move on to use contemporary and future imaginaries on cars and automated vehicles as our "figures to think with" (Haraway 2004, 331)

The first part outlines how the desire for transcendence has been invested in and nurtured through automatons, golems, robots, etc. in a historical perspective. A characteristic feature of these "Man plus" (Gray 2001) artefacts and creatures has been their prosthetic capacity combined with an inherent Janus face embodying both transgressive and destructive potentials. This first section maps out our approach to what can be called a cyborg-epistemology, which, in the following two sections, will be applied to contemporary imaginaries and (engineering) practices of (automated) technologies of movement such as the motor car. In the second part of the paper, we will focus on technologies of movement, more specifically, on how cars may form a part of our embodiment and sense of being, including their damaging and violent effects. In the third section, we will be more future-oriented by looking at autonomous transport futures and masculinity. Feminist scholars working on gender and technology have long argued that the symbolic link between men, masculinity, and cars is a cultural phenomenon that is continuously (re-)produced in cultural meaning-making (Faulkner 2001; Landström 2006; Wajcman 2004). While the interpellative experience of cars and their emotional and gendered dimensions have been discussed in feminist technology studies including our own work, the question how future autonomous vehicles may change such relations remains. With the advent of autonomous cars, how will this possibly change typical gendered connections between men, masculinity, and cars? Such trickster potentials will be further explored in the third section, which focuses more on imaginaries of autonomous mobilities and their gendered implications. A key point of this article is to investigate how technology and cyborgisation can be useful tools to understand the sleitmotif of male transcendence not only in the history of masculinity, but also in more contemporary and future forms and imaginaries of masculinity.

Transcendence is here understood in the spirit of de Beauvoir (1949), meaning that "[the] man has historically represented transcendence, given his participation in the activities that set up the world over and against na- 
ture" (Veltman 2006, 119). Despite the feminist critique of the concepts of transcendence and immanence, we nonetheless see the analytical value of thinking around the history of masculinity through transcendence. Even though our focus is on men and masculinity (in its many forms), this does not mean that women nor femininity are absent from our analysis. Our understanding of gender is relational; masculinity is not constituted separately from femininity (Connell 2006). We rather understand masculinity (and femininity) as a number of accumulated and changeable imaginings, practices, and positions that form the basis for masculine identities at a certain place and time (Nordberg 2005). We believe that masculinity is a discursive construct, meaning that both men and women may take up and identify with masculine and feminine positions and practices (Butler 1990). Technology forms a key part of the (re)creation and (re)production of gendered positions, practices, and identities (Landström 2007). As will be exemplified below, technology and gender are co-constructed and may express and reproduce conventional gender conventions - but they can also challenge them in fundamental ways (Lohan \& Faulkner 2004; Petersson McIntyre 2010).

\section{Cyborgs and masculine entanglements}

In the history of masculinity, we can see how masculinity and materiality have been closely connected and intertwined. We can also observe how the idea of Man is connected to transgressing the (hu)man flesh (Mellström 2020). In tracing that history, the cyborg is possibly the best metaphor to describe how human and nonhuman elements merge and form new ontological fusions. We believe that the metaphor of the cyborg works as an encompassing term for a self-regulating system that transcends the organic and the artificial, the smachinics, and the snon-machinics, which has been so characteristic for the conceptual as well as biological evolution of Man and masculinity. Although the term originates from an article by Clynes \& Kline (1960) in which the authors melt cybernetic and organic into one word, cyborgs have a long pre-history. The prolific cyborg theorist Chris Hables Gray points out that "cyborgs were a dream long before there were even machines" (Gray 2001, 4). Through religious sengineering , (hu)mankind has nourished the idea of human / non-human creatures in myths, cosmologies, tales, and stories of all kinds. A dominating feature of, for instance, Hindi and Taoist cosmology has been gods, goddesses, and creatures of all sorts that transgress borders between $(\mathrm{hu})$ mankind, the 
worlds of animals, gods, and machinic creatures. In many non-Western cosmologies, the idea of a sharp mind-body and/ or nature-culture dualism is simply not applicable.

This opens up for numerous forms of existence that involve organic and non-human components and often extend into the practices of everyday life. For instance, in Mellström's work among motor repair men in the Chinese-Malaysian diaspora of Penang, Malaysia (Mellström 2002, 2003a), he documented how tools and material objects are part of the concept of a person, or what makes up personhood in itself in a Taoist-Confucian cosmology. The idea of a self has, in the ontology of the local folk's beliefs, a polar relationship with >othersı. This leads to the idea that each particularity is a consequence of every other and determined by every other particularity. $(\mathrm{Hu})$ man existence is, then, constitutive in relation to >others and incorporates an extensive idea of subjectivity where the selfs is a subject that constantly is constituted and re-constituted in relation to >others and networks of >others, including machines. The motor mechanics envision >others in forms of tools and machines and such an embodiment of machines is a constitutive part of their sense of masculine entitlement. At the same time, it is deeply grounded in a belief system that is inherently transgressive with regard to anything that we label as human and non-human.

The cyborgic idea is a leitmotif that runs deep throughout the history of religion, art, science, and technology in the Western as well as the non-Western world. The desire of transcendence through artificial and organic self-extension has been invested in and nurtured through religious, mythological, and technical fantasy creatures such as automatons, golems, robots, etc. A characteristic feature of these artefacts and creatures has been their prosthetic capacity with an inherent Janus face. Historically as well as in relation to the future of masculinity, this points in two different directions: destructiveness on the one, emancipatory hopes of transcendence through cyborgisation on the other hand. Cyborgs are thus simultaneously political technologies and ambivalent creatures. Donna Haraway outlines the Janus face of such political technologies in the following quote:

From one perspective, a cyborg world is about the final imposition of a grid of control on the planet, about the final abstraction embodied in a Star Wars apocalypse waged in the name of defence. From another perspective, a cyborg world might be about lived social and bodily realities in which people are not afraid of their joint kinship with animals and machines, not afraid of perma- 
nently partial identities and contradictory standpoints. The political struggle is to see from both perspectives at once (Haraway 1997, 5).

Haraway's symbolic appropriation of the concept was crystallised in her famous sentence "I'd rather be a cyborg than a goddess" in her Cyborg manifesto from 1985. The manifesto was in many ways a symbolic turning point for a feminist intervention into a totally male-dominated world. Haraway opened up an emancipatory space for a symbolic appropriation of technological intimacy as entanglement, reciprocity, proximity, and affinity with different materialities that has become the key of contemporary feminist critical posthumanism and new materialism (Alaimo 2016; Barad 2007; Braidotti 2013).

In the history of masculinity, the dark and destructive political undertone of a cyborg-epistemology formulated as »thesis, anti-thesis, synthesis, prosthesis" (Gray 2001, 189) can for instance be traced in various forms of military masculinities. Cyborgisation in the military is a long-standing theme with many strands of thought in relation to power and pleasure, eroticism, lust, submission, penetration etc. Lewis Mumford (1946) argued that the very first machine was an army consisting of men and their weapons as the moving parts. Mumford pointed out how weaponry and the disciplining of individual bodies / soldiers into cleanly working parts as well as the military's fostering of automation have contributed to an ideal of masculinity which has shaped endless generations of men. It has also formed many post-war generations of prosthetic and disabled men. For instance, Boaz Neumann shows how the prosthetic body came to be part of a masculine ideal in Weimar Germany »in the construction and shaping of a prosthetic `New Man« (Neumann 2010, 94), and which in itself extended the embodied experiences of a whole generation of men.

The technoerotic marriage between weaponry and masculinity is thus one pertinent expression of transcendence and prosthetic integration of the machinic. A foundational base for portraying the masculine hubris of transcending human life via technology is however something that often goes back to the Greek mythology of the Titan Prometheus. He gave the humans the gift of fire and the skill of metalwork, an action for which Zeus punished him by chaining him to a rock and letting an eagle eat the Titan's regrowing liver every day anew. However, after many years, Herakles killed the eagle with one of his arrows and freed Prometheus. In the myth of Prometheus, life, death, creation, destruction, technology, and masculinity are symbolically woven together. The freeing of Prometheus has been interpreted as humanity overpowering the gods by obtaining the 
knowledge to make fire. As the myth of Prometheus also carries the Janus face of destruction versus creation, the unbound Prometheus can be seen as an ambivalent figure.

This ambivalence is also the main theme in Mary Shelley's famous novel "Frankenstein - or the Modern Prometheus«. Victor Frankenstein, the scientist, is envisioning human life without women by creating a monster in his marriage with science and his desire for fame, immortality, and transcendence. The monster is eventually abandoned and Frankenstein is not taking any responsibility for his creation. The monster, or creature, seeks kindness and affection, but it is shunned and repulsed by everyone he comes into contact and is thus forced to death and destruction. In comparison to his ancient colleague, the Modern Prometheus is a one-sex figure. The ancient Prometheus is credited with the creation of man and women from clay and defying the gods by stealing the fire, an act that enabled the progress of science and technology. However, with the modern Prometheus, the power of creation is only in the hands of men (Berner 1999). The ambivalence and desire for transcendence is also a theme for some classical work in the sociology of science. For instance, Easlea (1983) and Cohn (1987) show how the nuclear arms race and the development of nuclear bombs are closely connected to the gendering of nuclear weapons. They were male descendants and (code)named as such. The bombs that detonated over Hiroshima and Nagasiki were named `Fat Man` and \Little Boy<. The nuclear bomb was generally referred to as `Oppenheimer's baby after its inventor and leader of the Los Alamos group, Robert Oppenheimer. Conveniently, National Baby Institution in the U.S. honored him with the "Father of the Year» award in 1945.

The studies of nuclear power for military purposes probably illustrate the deep-rooted theme of transcendence in its most mortal and brutal form. However, the cyborgic entanglements of technology and masculinity obviously also have forms that are more mundane. It is this mundanity we will turn to in the following by focusing on technologies of movement.

\section{Men, masculinity, and technologies of movement}

Cars and car driving are some of the arenas where masculinity is most clearly constructed around intimacy, technology, and cyborgisation, as exemplified in numerous cases of popular culture and daily practices in and around cars. Motor vehicles of various kinds build on what has been de- 
scribed as a cyborgic fusion of man and machine, where corporeal experiences are tightly interlinked with embodied control and power (Lohan \& Faulkner 2004; Lupton 1999). Car cultures, car driving, and gendered identity formations through motor vehicles are intertwined with issues of embodiment, space, and risk-taking of various forms (Uteng \& Cresswell 2008). Boundaries between man and machine have been theorized as products of hybrid subjectivities - such as "cyborgs", "carsons" or "driver-car" (Böhm et al. 2006; Dant 2004; Lupton 1999; Michael 2001). The combination of the driver and car as a cyborg figure or driver-car-sassemblage explicates their situatedness within the much broader sociotechnical network of automobility, and is in itself a necessity to perform car driving in the first place (Dant 2004; Lupton 1999).

While these discourses confuse any clear statements on what mobility hybrids are, it is probably more important to consider what these relations >do . Depending on what mode of mobility is emphasised, different ssense experiences are produced, including different ways of knowing the world in contradictory ways (Bissell et al. 2018; Nixon 2012). Denver Nixon draws on Urry's work $(2006,2007)$ to illustrate this point. On the one hand, cars are not only "extension(s) of the driver's body" (Urry 2006, 24). but also become part of us, "of the senses so that the car-driver can feel it's very contours, shape, and relationship to that beyond its metallic skin" (Urry 2007, 127). On the other hand, as Urry also argues, "sights, sounds, tastes, temperatures and smells get reduced to the two dimensional view through the car windscreen" (Urry 2007, 129) and "the environment beyond that windscreen is an alien other, kept at bay through the diverse privatizing technologies incorporated within the car" (Urry 2006, 23). As parts of us, cars may extend us, but also come with some clear limitations: "This apparent contradiction is likely owed to the complex nature of hybrids, where an assemblage may possess both beneficial and detrimental affordances" (Nixon 2012, 1663). These contradictions clearly map on to the prosthetic capacity of cars with their inherent Janus faces by being both emancipatory and destructive at the same time.

The emancipatory side of automobility relates to driving pleasure and the many ways that car driving entails emotional kicks and pleasures for its users. In order to understand why cars, car driving, and mobile technocultures develop such a profound attraction and continuation despite their well-known ecologically damaging effects, one needs to understand the investments of social and emotional forms that many men and women develop with cars (Balkmar \& Joelsson 2009). Deborah Lupton, for example, has argued that there is a sstrong element of eroticism inherent in the 
power offered by the car", which is related to "drivers' belief that they can take charge over this power and manipulate it for their own ends" (Lupton 1999, 60). The powerful embodied emotional connection between (mobile) machine and human bodies, including the risk of dying, becomes, at least for some drivers, the very "fuel« for living (Balkmar 2012, 221). Take, as an example, Janne, an owner of a vintage customized Ford, in which he has installed a so-called Nitrous Oxide System (NOZ), resulting in a much more powerful combustion (Balkmar \& Joelsson 2010). For him, the excitement in driving the car equals with what the hero of the movie Highlander (a fantasy action film on the ages-old battle between immortal warriors) feels when receiving extra-terrestrial divine power from heaven.

"Yes, that's how it feels, like reaching for the sky and receiving the force, when you push the nitrous oxide switch it's like you get it all from heaven " (Balkmar 2012).

The speed-based practices Janne refers to emphasise the car's capacity to extend the self and what the body can feel and perform (Balkmar \& Joelsson 2010). In fact, for car modifiers like Janne, speed enables to use their cars as sites of corporeal significance, as extensions of self with which to experiment with particular (divine) states of being (Bengry-Howell 2005). In Janne's case, the car is clearly a site of transcendence, enabling him to feel as if embodying the powers of an immortal Scottish swordsman (Balkmar 2012).

The other side of the Janus face is destructive and violent. Investments in speeding are clearly a damaging practice, killing foremost men, and have done so since the early age of industrialisation (Anshelm 2005). While it is well known that men, more often than women, are causing accidents, injuries, and deaths of other road users across the globe, it is less common to place drivers' "emotionally-affirmative experiences alongside the more potential violating effects of movement technologies" (Balkmar \& Joelsson 2009, 125) Or, as Jeff Hearn mentions in the context of "men's violences":

In the dominant automobilic system, fast objects meet soft flesh; violence is implicated, condoned, and naturalized, with mainly men causing accidents, injuries, deaths of other men, women, children, animals and damage to the Earth, and nature, as a form of very largely men's violences (Hearn 2015, 158).

From this perspective, the many ways that motor vehicles can be damaging, threatening, and perform outright violence are put in focus. The double-edged cyborg figuration allows us to consider the Janus face of automobility more fully, namely to consider how the pleasurable, subjec- 
tive experiences and identity work performed through car driving, as exemplified above, also encompass bodily and spatial violations of various kinds - including environmental damage (Balkmar \& Joelsson 2009, 125). However, with the advent of automated vehicles and transport futures, the car-human relations elaborated above may unfold in unexpected directions.

\section{Technology, masculinity and (automated) transport futures}

The automobile and the automobility system in total have had major impacts on social life during the $20^{\text {th }}$ century Urry (2006). Automobility as a concept identifies one of the most important socio-technical institutions, namely the motorcar as ideological formation, through which modernity is organised (Böhm et al. 2006; Urry 2004). Automobility not only changed society, but also what people may do and become (Urry 2007). With autonomous vehicles, however, the next major revolution in transportation technology is expected. Bissell et al. (2018) argue that "[a]utonomous vehicles are one of the most highly anticipated technological developments of our time, capturing the popular imagination arguably more so than any other transportation technology over the past half century." (Bissell et al. 2018, 2). Autonomous mobility also comes in the Janus face of destructiveness and emancipation, either as "utopias of mobilities" or as "dystopias of malfunctioning technology« (Freudendal-Pedersen \& Jensen 2012, cited in; Hildebrand \& Sheller 2018, 64). However, autonomous vehicles in popular debates are often constructed as technological fix, ascribed the potential to solve current transport problems in an instrumental way, be it problems with congestion, pollution, or road-traffic crashes (Balkmar \& Mellström 2018; Bissell et al. 2018; Kröger \& Weber 2018).

We take these imaginations of future transportation as the basis for further speculations on the implications for masculinity, cyborgisation, and intimacy in the context of (automated) transport futures. Judging by popular debates, in the (near) future, drivers will be reassigning the driving task to car designers, engineers, and networked computers to become passengers (Laurier \& Dant 2012). As Hildebrand and Sheller suggest, automated mobility disrupts more than dominant ideas about control and driving, "but also how the entire system of driving implies, affords, and enhances multiple senses, thoughts, and feelings (e.g., of safety, power, security, citizenship, etc.) on an individual and societal level" (Hildebrand \& Sheller 2018, 65). With reference to the close, embodied con- 
nection between driver and car as outlined above, with autonomous cars programmed to follow traffic regulations and thereby drive serror frees, many of the core values / problems related to masculinity, risk, and driving pleasure are imagined to be reduced in future transport systems (Berscheid 2016; Laurier \& Dant 2012).

However, the redistribution of agency that follows from a transportation system based on more self-driving vehicles may also come to change men's relationships to cars in a more profound way (Berscheid 2017). Several possible consequences can be noted, one is individual drivers' ’loss‘ of driving pleasure, control, and car ownership. Consider how the typically active "masculine act of driving would transformed into a much more passive relation with cars as passengers (Hildebrand \& Sheller 2018). Instead, with automated vehicles, dwelling in the vehicle comes much more in focus, which, in turn, might open up for a possible sfeminization of automobility, potentially even de-gendering future car cultures (Balkmar \& Mellström 2018; Hildebrand \& Sheller 2018; Kröger \& Weber 2018; Urry 2006).

A related consequence is occupational: Increased automation may potentially have severe implications for the job market in the transportation business, including transformations of required skills (Berscheid 2016; Bissell et al. 2018; Laurier \& Dant 2012). Along with an increased redistribution of agency and transformation of required skills come scenarios of re-segregation concerning men and masculinity. Here, we have suggested the possibility that working-class men and their specific masculinity currently dominating the transportation system will lose ground and a professional, calculating rationality of technical specialists will become more influential, in particular men and masculinities in sectors such as IT, robotics, software development, and engineering (Balkmar \& Mellström 2018; Wajcman 1991).

Considering how automated vehicles relate to gendered power differentials, empowerment, and potentially emancipatory outcomes, we may expect contradictory consequences. While increased automation may change gender relations in and around motor vehicles, any emancipatory potentials regarding posthuman masculinities remain unclear. As Bergman et al. argue, "much future mobility visioning is used to support the status quo, rather than to explore a variety of futures with diverse portrayal of people, behaviour and mobility« (Bergman et al. 2017, 165). We can already see the contours of both emancipatory and segregating potentials in the ways car manufacturers and other innovators imagine their future users. For example, autonomous cars can be presented as either empowering the 
currently less mobile or mmobility poor (such as the Google car), or as high-tech luxurious designs for those who can afford to pay for exclusive freedom and privacy such as Mercedes Luxury in motion (Manderscheid 2018). However, as Hildebrand and Sheller note, car manufacturers in their audio-visual previews of autonomous vehicles still connect control and mastery over the vehicle with the white male driver. Even though autonomous vehicles clearly draw on futuristic scenarios with some clear potentials to counter some current sman-made problems and excluding effects associated with automobility, autonomous vehicles nevertheless seem to remain an item of individual consumption with similar sign-values associated with the current motorcar (such as status, class, power, and masculinity) (Hildebrand \& Sheller 2018).

\section{Discussion and conclusions}

In this article, we have elaborated on the potentials of the cyborg figuration as a thinking technology with various forms of technology and materiality. We have argued for opening up the theoretical possibilities and repertoire for thinking around technologies of movement. We have done so by revisiting the historical foundation of the cyborgic entanglements of technology and masculinity, and shown how this ambivalence can be used to think around contemporary and future technologies of movement including their affective and emotional aspects.

We have argued that masculinity has a long history of wishful transcendence by merging different forms of organic and non-organic materiality. It is an enduring theme in the history of humankind and always comes in the Janus face of destruction versus creation. The special masculine hubris of transcending $(\mathrm{hu})$ man life via technology and materiality is a gigantic challenge for all contemporary and future technological developments, such as automated vehicles and the full automation of technologies of movement previously discussed. The modern Prometheus unbound has, throughout industrialism and modernity, almost exclusively been an ambivalent one-sex smonster. It is therefore critical to include a wider range of positionalities and experiences. Here we find Sheller's argument particularly useful, that we need to consider »the power differentials that come into play in any form of mobility and the different affordances that different people are able to make use of or appropriate in becoming mobile or not" (Sheller 2014). 
As we have discussed, autonomous vehicle technologies do not offer quick fix solutions for a more inclusive transport system. Instead, we need to be cautious how such technologies and related imaginaries may produce new or maintain existing forms of social inequality (Bissell et al. 2018)

In masculinity studies, we are currently witnessing a growing interest for the affective and emotional aspects of how masculinity is perceived and performed. For instance, Reeser \& Gottzén argue that "we need to understand affective masculinities as not only embodied expression regulated by gendered emotions regimes but also as the action potential of human and non-human bodies" (Reeser \& Gottzén 2018, 149).

Reeser and Gottzén's work on masculinity and affect is one example of how the distinctions between human-non-human: machinic/somatic; material/organic, are being problematized in contemporary masculinity studies. A conclusive argument in their work is that male bodies exist in networks in which affects are channelled through non-discursive and charged materialities. As we are witnessing an interesting opening for an ontological politics in masculinity studies that challenge old and gendered baselines like rationality/irrationality or abstract/concrete, we are also witnessing an opening with regard to how we can conceptualise contemporary as well as future technologies of movement.

\section{References}

Alaimo, Stacy (2016): Exposed: Environmental Politics and Pleasures in Posthuman Times. Minneapolis.

Anshelm, Jonas (2005): Rekordårens tbc. Debatten om trafiksäkerheten i Sverige 19451965. Tema T rapport Nr. 44. Tema Teknik och social förändring. Linköping.

Balkmar, Dag (2012): On Men and Cars: An Ethnographic Study of Gendered, Risky and Dangerous Relations. Dissertation. Linköping: Linköping Universitet.

Balkmar, Dag (2014): Negotiating the "plastic rocket«: masculinity, car styling and performance in the Swedish modified car community. In: NORMA: International Journal for Masculinity Studies 9 [3], 166-177.

Balkmar, Dag/Joelsson, Tanja (2009): Burning Rubber, Marking Territory: Technology, Auto-Erotic Desires and Violating Mobility. In: Åsberg, Cecilia et al. (Hrsg.): Gender Delight, Science, Knowledge, Culture and Writing. ... for Nina Lykke. Linköping, 117-126.

Balkmar, Dag/Joelsson, Tanja (2010): Den bioniske mannen på autoerotiska äventyr mäns risktagande i trafikrummet. In: NORMA: Nordic Journal for Masculinity Studies 5 [1], 27-44.

Balkmar, Dag/Joelsson, Tanja (2012): Feeling the speed - the social and emotional investments in dangerous road practices. In: Jansdotter Samuelsson, Maria/Krekula, Clary / Åberg, Magnus (Hrsg.): Gender and Change. Karlstad, 37-52. 
Balkmar, Dag/Joelsson, Tanja (2014): The dangerous other? Towards a contextual approach to men's risk-taking with motor vehicles. In: Lander, Ingrid/Signe, Ravn (Hrsg.): Masculinities in the Criminological Field:. Control, Vulnerability and RiskTaking. London, 187-202.

Balkmar, Dag/Mellström, Ulf (2018): Masculinity and Autonomous Vehicles. A Degendered or Resegregated Future System of Automobility. In: Transfers: Interdisciplinary Journal of Mobility Studies 8 [1], 44-63.

Barad, Karen (2007): Meeting the Universe Halfway: Quantum Physics and the Entanglement of Matter and Meaning. Durham.

Beauvoir, Simone de (1993): The Second Sex. London.

Bengry-Howell, Andrew (2005): Performative Motorcar Display: the Cultural Construction of Young Working Class Masculine Identities. Dissertation, Birmingham: University of Birmingham.

Bergman, Noam/Schwanen, Tim/Sovacool, Benjamin K. (2017): Imagined people, behaviour and future mobility: Insights from visions of electric vehicles and car clubs in the United Kingdom. In: Transport Policy 59, 165-173.

Berner, Boel (1999): Perpetuum Mobile? Teknikens utmaningar och historiens gång, Arkiv.

Berscheid, Anna-Lena (2016): Masculinity in danger? The autonomous car as game changer. Cars In / Of Culture: Mobility, Materiality, Representation, Oxford, 13.-15.09.2016. Online unter: www.inter-disciplinary.net/critical-issues/wp-content/uploads/2016/08/ AnnaLenaBerscheid-dpaper-cars1.pdf (31.05.2017).

Berscheid, Anna-Lena (2017): Masculinity in danger? Autonomous cars as cultural challenge. Online: www.2025ad.com/in-the-news/blog/automated-driving-and-masculin ity/ (31.05.2017).

Bissell, David et al. (2018): Autonomous automobilities: The social impacts of driverless vehicles. In: Current Sociology, 1-19.

Böhm, Steffen et al. (Hrsg.) (2006): Against Automobility, Malden.

Braidotti, Rosi (2013): The Posthuman. Cambridge.

Butler, Judith (1990): Gender Trouble: Feminism and the Subversion of Identity. New York.

Clynes, Manfred E./Kline, Nathan S. (1960): Cyborgs and space. In: Astronautics 5 [9], 26-27, 74-76.

Cohn, Carol (1987): Sex and death in the rational world of defense intellectuals. In: Signs 12 [4], 687-718.

Connell, Raewyn (2006): Masculinites, Cambridge.

Dant, Tim (2004): The Driver-car. In: Theory, Culture and Society 214/5, 61-79.

Easlea, Brian (1983): Fathering the Unthinkable, London.

Faulkner, Wendy (2001): The technology question in feminism: a view from feminist technology studies. In: Women's International Forum 24 [1].

Freudendal-Pedersen, Malene/Jensen, Ole B. (2012): Utopias of Mobilities. In: Hviid Jacobsen, Michael/ Tester, Keith (Hrsg.): Utopia: Social Theory and the Future. Aldershot, 197-217.

Gray, Chris Hables (2001): Cyborg Citizen: Politics in the Posthuman Age. London.

Haraway, Donna (1997): Modest_Witness@Second_Millennium. FemaleMan@ _Meets_ Onco-Mouse: Feminism and Technoscience. New York.

Haraway, Donna (Hrsg.) (2004): The Haraway Reader. New York, London. 
Hearn, Jeff (2015): Men of the World: Genders, Globalizations, Transnational Times. Los Angeles.

Hildebrand, Julia M. / Sheller, Mimi (2018): Media Ecologies of Autonomous Automobility. Gendered and Racial Dimensions of Future Concept Cars. In: Transfers: Interdisciplinary Journal of Mobility Studies 8 [1], 64-85.

Kröger, Fabian/Weber, Jutta (2018): Introduction: Autonomous Driving and the Transformation of Car Cultures. In: Transfers: Interdisciplinary Journal of Mobility Studies 8 [1], 15-23.

Landström, Catharina (2006): A Gendered Economy of Pleasure: Representations of Cars and Humans in Motoring Magazines. In: Science Studies 19 [2], 31-53.

Landström, Catharina (2007): Questioning feminist technology studies 8 [1], 7-26.

Laurier, Eric/Dant, Tim (2012): ,What else we do while driving towards the driverless car`. In: Grieco, Margaret/Urry, John (Hrsg.): Mobilities: New Perspectives on Transport and Society. Farnham, 223-244.

Lohan, Maria / Faulkner, Wendy (2004): Masculinities and Technologies. Some Introductory Remarks. In: Men and Masculinities 6 [4], 319-329.

Lupton, Deborah (1999): Monsters in Metal Cocoons. ২Road Rage and Cyborg Bodies. In: Body \& Society 5 [1], 57-72.

Manderscheid, Katharina (2018): From the Auto-mobile to the Driven Subject. Discursive Assertions of Mobility Futures. In: Transfers: Interdisciplinary Journal of Mobility Studies 8 [1], 24-43.

Mellström, Ulf (1999): Män och deras maskiner. In: NORMA.

Mellström, Ulf (2002): Patriarchal machines and masculine embodiment. In: Science, Technology \& Human Values 27 [4], 460-478.

Mellström, Ulf (2003a): Masculinity, power and technology: a Malaysian ethnography, Aldershot.

Mellström, Ulf (2003b): Teknik och maskulinitet: män och deras maskiner. In: Berner, Boel (Hrsg.): Vem tillhör tekniken?: kunskap och kön i teknikens värld. Lund, 55-76.

Mellström, Ulf (2004): Machines and masculine subjectivity, technology as an integral part of men's life experiences. In: Men and Masculinities 6 [4], 368-383.

Mellström, Ulf (2012): Changing affective economies of masculine machineries and military masculinities? From Ernst Jünger to Shannen Rossmiller. In: Masculinities and Social Change 2 [1], 422.

Mellström, Ulf (2020): Masculinity Studies and Posthumanism. In: Gottzén, Lucas / Mellström, Ulf/Shefer, Tamara (Hrsg.): Routledge International Handbook of Masculinity Studies. London.

Michael, Mike (2001): The Invisible Car: The Cultural Purification of Road Rage. In: Miller, Daniel (Hrsg.): Car-Cultures. Oxford, New York.

Mumford, Lewis (1946): Technics and civilisation, Chicago.

Neumann, Boaz (2010): Being Prosthetic in the First World War and Weimar Germany. In: Body \& Society 16 [3], 93-126.

Nixon, Denver (2012): A sense of momentum: mobility practices and dis/embodied landscapes of energy use. In: Environment and Planning 44 [7], 1661-1678.

Nordberg, Marie (2005): Jämställdhetens spjutspets?: manliga arbetstagare i kvinnoyrken, jämställdhet, maskulinitet, femininitet och heteronormativitet. Dissertation, Göteborg: Göteborg Universitet. 
Petersson McIntyre, Magdalena (2010): Bara den inte blir rosa, genus design och konsumtion i ett svenskt industriprojekt, Göteborg.

Reeser, Todd W. / Gottzén, Lucas (2018): Introduction: Masculinity and affect: new possibilites, new agendas. In: NORMA: International Journal for Masculinity Studies 133/4, 145-157.

Sheller, Mimi (2014): Mobility Justice. In: Wi: Journal of Mobility Culture 8 [1].

Urry, John (2004): The sSystem 25-39.

Urry, John (2006): Inhabiting the car. In: Sociological Review 54s1, $17-31$.

Urry, John (2007): Mobilities. Malden.

Uteng, Tanu Priya / Cresswell, Tim (Hrsg.) (2008): Gendered Mobilities. Aldershot.

Veltman, Andrea (2006): Transcendence and Immanence in the Ethics of Simone de Beauvoir. In: Simons, Margaret A. (Hrsg.): The Philosophy of Simone de Beauvoir: Critical Essays. Bloomington, 113-131.

Wajcman, Judy (1991): Feminism Confronts Technology. Cambridge.

Wajcman, Judy (2004): Technofeminism. Cambridge. 